\title{
Modelling by Finite Element Method of the twin- screw of a press for obtaining grape seed oil
}

\author{
Carmen Vasilachi ${ }^{1 *}$ and Sorin-Stefan Biriş $^{2}$ \\ ${ }^{1}$ National Institute of Research - Development for Machines and Installations Designed to Agriculture \\ and Food Industry - INMA, Bucharest, Romania \\ ${ }^{2}$ University Politehnica Bucharest, Faculty of Biotechnical Systems Engineering, Romania
}

\begin{abstract}
This paper is about getting grape seed oil using a twin-screw press. Grape seed oil is a by-product of the wine industry due to the need to reduce the amount of waste, but at the same time it has been found that this oil is an excellent ingredient that can be used in many industries. It is assumed that the use of twin-screw is more efficient than single-screw extraction due to the larger pressures that are created inside the press chamber. This study focuses on the finite element method analysis of how the press process is carried out. Using the finite element method, we can get an overview of how the pressure acts on the sides of the twin-screw, how it influences the temperature but also other process factors. When we have all these, we can begin optimizing the twin-screw press process.
\end{abstract}

\section{Introduction}

Due to the imminent exhaustion of the fossil resources which are at present being excessively used in the petrochemical industry a huge amount of effort is being made to discover a viable new alternative, a renewable solution for raw materials to be used instead of these resources[1]. In order for this alternative to be considered it has to include usage of renewable resources, it has to have an accessible price, it needs to be easily accessible by an industry, it needs to be produced widely across the globe and it should be considered practically unlimited. Another further benefit which is desired from this research is that the derived products of these renewable raw materials (E.g.: polyurethanes, lubricants, fuels) are to be biodegradable and also to have a proper integration with the natural cycle, $[2,3,4]$.

Taking into consideration the situation from the petrochemical industry where more environmentally friendly alternatives are being looked for, the extraction of oils from vegetable materials is starting to become an opportunity worth exploiting. Grape seed oil can be used in industrial applications as well as a rich source of bioactive compounds (E.g.: essential fatty acids, tocopherols, tocotrienols, polyphenols, flavonoids, tannins and phytosterols), [5].

\footnotetext{
*Corresponding author: carmen.vasilachi@gmail.com
} 
These bioactive compounds in oils can have a various composition depending on the grape variety, on the maturity level on the conditions and locations in which the grapes have been grown as well as the type of extraction technique used. The extracted grape seed oil benefits human health greatly due to its high unsaturated fatty acids content alongside natural antioxidants compounds. Similar to other cold pressed oils the grape seed oil is used in food, cosmetics and pharmaceutical industries mostly due to its composition and properties, [6].

As a sub-product, grape seed oil is obtained through harvesting the grape marc which in turn is part of the wine industry. Throughout the year in the wine industry a little over $20 \%$ of the grapes become waste material out of which between $38-52 \%$ are dried calories seeds from the dry matter. Between 8 and $20 \%$ of oil can be obtained from this quantity of grape seeds and it's also worth mentioning that this would be the most economic and efficient way to deal with the unused leftover material, [7]. As an example we can use the numbers reported by Castilla-La-Manca which is a region located in the center of Spain that runs one of the largest wine producing industry in the world. Their annual waste sums up about 100000 tons of grape seeds over one year, [8]. In order to extract grape seed oil from the seeds a mechanical process can be used and obtain the oil through screw extrusion or a solvent process can be used and obtain the oil in this way. The most preferred extraction method which coincidently is also the efficient one because it ensures the superior quality of the extracted oil is the mechanical pressing. Through mechanical pressing we will benefit from low process temperatures without the solvent but unfortunately we will also obtain low levels of oil, usually between 55 and $95 \%$ depending on the processed material, [9]. The mechanical screw extraction has been a subject of study for a wide variety of oil producing seeds (such as linseed, canola and grape seed). These studies have shown that the factors which contribute to increase the temperature and pressure in the screw press chamber benefit the oil yield greatly. By changing the nozzle's diameter through which the solid parts are being discharged and also by adjusting the rotation speed of screw inside the press we can adjust the factors to benefit the production of grape seed oil. It was noticed throughout testing that the lower the screw speed and the smaller the nozzle opening is the more oil is yielded, [10]. There are other ways of increasing the oil yield which consist of seed pre-treatments such as degreasing, cooking, moisturizing conditioning. Moisturizing conditioning has an essential role to play in the extraction of oil since the optimal moisture content which determines the oil yield can be discovered based on the seed variety. Cooking the seed before extraction could potentially cause oil degradation even though it increases the oil yield. Because of the many pre-treatments downsides cold pressing is usually to go-to method preferred because of the retention of healthier components such as antioxidants which increase the nutritional value of the pressed oil. It is however possible to increase the composition and quality of the oil by making sure that during the pressing process the temperatures reached would stay constantly between 60 and $68^{\circ} \mathrm{C},[11,12]$.

Just as mentioned above, mechanical single screw extractions will have a lower yield result. Taking this matter into consideration has made researchers try to implement new ways of increasing the yield of pressed oil by using a method called twin-screw extrusion.

The first twin-screw extruder was developed by Coignet in 1869 for the concrete industry. The first oilseed oil twin-screw extractors were developed in the 1990s, [13].

The twin-screw extrusion method is an innovative piece of technology which has continuously growing applications in industries such as the grain industry, the polymers industry, the pet food industry and the paper industry. Even though at present this technology is not yet applied in the seed oil extraction industry it presents itself as a very promising technique to be used for a sustainable extraction of vegetable oil and also as a way of ruling out some of the problems found in single-screw extraction methods such as the relatively small amount of oil extracted, the excessive heat generated during the 
extraction because of friction, the high energy consumed by the process and the deterioration present in the oil and clod quality, [14].

It is considered very likely that the twin-screw press could be a solution to the above mentioned problems since it provides a much higher transport force and a much better shredding and mixing interface between the two worm screws. After performing a set of lab tests to see how the twin-screw press and the single-screw press handle sunflower seeds when trying to obtain sunflower oil through this method the tests showed that the twinscrew technology has a much greater efficiency when extracting oil from oilseeds, it yields a high-quality oil and meal even if the materials are not the type that could be easily machined as in the case of peeled sunflower seeds pressed by a single-screw press. Another advantage of the twin-screw press is that it makes it possible to discard the pre-treatments such as cooking and peeling the seeds and also the roasting and dripping pre-treatments as well. While performing the tests it was noticed that the energy consumption during the process was much lower than the one for single-screw presses. After multiple experiments it was noted that the twin-screw press has a better performance at milling when the seeds are small just like sesame and rape seeds are, but it is still unknown whether the press can perform just as good when string low-oil seeds are used like soybean seeds.

To get a more intense mechanical machining of the seeds a design with counter-rotating and intermittent screws was thought of, a design which generates longer retention times and high shearing pressure at the upper interconnection of the screws, [14]. This is an important machining advancement in this industry since the ability to configure the screw with a wide variety of elements that have a varying thread profile and also making it possible to have different working sections into the same extruding machine is an important and beneficial change. As such an advancement of this sort is presented in literature as having been developed for sunflower seeds presses for the extraction of sunflower oil where it was noticed that the sunflower seeds have undergone thermomechanical pressures during the extraction process, [15]. The below Figure 1 presents the structure of an extruder and that of the twin-screw profile.

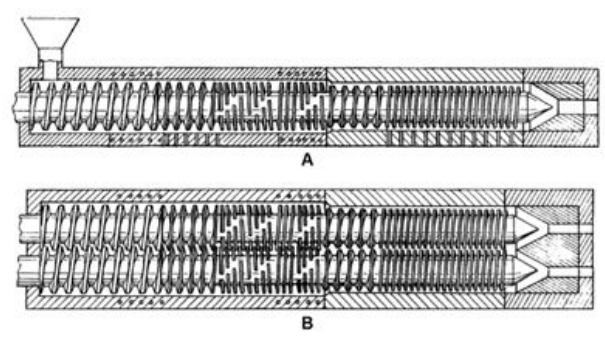

Fig. 1. The twin-screw extruder design comprising two different pressing sections and developed; A. Schematic view through a vertical plane running through one of the screw axes; B. Schematic view through a transversal plane showing both screw axes [13].

Because of the possibility of having different configurations for the twin-screws the press becomes more versatile. The first element present in the configuration of the right screw is a section with a certain pitch which is special for its ability to ensure constant material transportation and a high material pumping capacity and which is also used in the extruder feed or in the compression section. On the left screw the pitch configuration is referred to as a reversed screw member. This element exerts a transportation force on the material present in the press which is opposite to the direction flow which in turn causes intense shearing of the material. As a conclusion successively positioning different screw combinations in the press results in a more effective material compression, the creation of a 
dynamic plug and a good separation which is caused by the efficient pressure build-up, [16].

The objective of this study was to show how the compression of the double screw during the pressing process works and to show that an extruder with two co-rotating screws can be used to more effectively extract grape seed oil by mechanical pressing. The study's subject also proposes the evaluation of the effects that the screw configuration, the screw pressure and the screw rotation speed have on oil extraction efficiency.

\section{Materials and methods}

In this study, grape seeds were used as raw material. Initially grape seeds have a moisture content between $40-50 \%$ and must be reduced to about $5-8 \%$ in the drying chamber. In the literature, the following texture parameters for grape seeds were obtained (Table 1): seed break force $\left(\mathrm{N}\right.$, as $\left.\mathrm{F}_{\mathrm{s}}\right)$, seed break energy $\left(\mathrm{mJ}\right.$, as $\left.\mathrm{W}_{\mathrm{s}}\right)$, seed $\mathrm{N}\left(\mathrm{N} \cdot \mathrm{mm}^{-1}\right.$, as $\left.\mathrm{E}_{\mathrm{s}}\right)$ and seed deformation index $\left(\%\right.$, as $\left.\mathrm{DI}_{\mathrm{s}}\right)$.

In this study, we chose the mechanical properties of the material, grape seeds, to be part of the D density class where we encounter the greatest breaking force.

The main objective of this paper was to find a way to highlight how forces and deformations propagate into the double screw during the compression process in order to optimize the energy consumption required for processing. Therefore, it is now possible to try using the finite element method. This method is the most advanced engineering tool for calculating the numerical and mathematical modelling of complex phenomena involving the propagation of stress and strain fields in continuous environments. In this paper is presented a two-dimensional FEM model for the analysis of double screws subjected to compression through the axial and lateral directions.

Tabel 1 Seed mechanical properties of sorted Cabernet-Sauvignon grapes harvested at different density class [17]

\begin{tabular}{|c|c|c|c|c|}
\hline Density class & $\mathrm{F}_{\mathrm{s}}[\mathrm{N}]$ & $\mathrm{W}_{\mathrm{s}}[\mathrm{mJ}]$ & $\mathrm{E}_{\mathrm{s}}[\mathrm{N} / \mathrm{mm}]$ & $\mathrm{DI}_{\mathrm{s}}[\%]$ \\
\hline $\mathrm{A}$ & $44.5 \pm 7.8$ & $11.9 \pm 3.2$ & $69.7 \pm 15.4$ & $31.4 \pm 5.7$ \\
\hline $\mathrm{B}$ & $42.2 \pm 9.1$ & $11.8 \pm 4$ & $70.1 \pm 13.1$ & $29.7 \pm 5.9$ \\
\hline $\mathrm{C}$ & $45.7 \pm 7.9$ & $12.6 \pm 3.5$ & $77.2 \pm 13.9$ & $30.2 \pm 4.9$ \\
\hline $\mathrm{D}$ & $47.5 \pm 9.4$ & $12.6 \pm 3.4$ & $83.2 \pm 13.5$ & $28.2 \pm 4.2$ \\
\hline E & $44.6 \pm 9.2$ & $12.3 \pm 5.3$ & $81 \pm 14$ & $28.9 \pm 7.6$ \\
\hline
\end{tabular}

All data are expressed as average value \pm standard deviation. Fs $=$ berry seed break force, Ws $=$ berry seed break energy, Es = berry seed Young's modulus of elasticity, DIs = berry seed deformation index (distance of seed break point $/ \mathrm{seed}$ height $\mathrm{x}$ 100). $\mathrm{A}=1081 \mathrm{~kg} \cdot \mathrm{m}^{-3}, \mathrm{~B}=1088 \mathrm{~kg} \cdot \mathrm{m}^{-3}, \mathrm{C}=1094$ kg. $\mathrm{m}^{-3}, \mathrm{D}=1100 \mathrm{~kg} \cdot \mathrm{m}^{-3}$, and $\mathrm{E}=1107 \mathrm{~kg} \cdot \mathrm{m}^{-3}$

To obtain a double-screw FEM model, we used ANSYS Polyflow software that provides advanced fluid dynamics technology to solve different tasks in different industries. ANSYS Polyflow software is generally used to minimize physical prototypes in product manufacturing or to reduce thickness variation to improve product quality to substantially reduce costs and save time. Product quality is improved by running trial and error processes with ANSYS Polyflow rather than by testing changes on the production line. 
A twin-screw model was created in the Catia program, after which it was imported into the ANSYS Polyflow software. For this study a piece of double screw was chosen to determine the flow rate generation. Dimensions are given in Table 2.

Table 2. Dimensions of screws and barrel.

\begin{tabular}{|c|c|}
\hline Element & Dimensions [mm] \\
\hline Screw pitch & 40 \\
\hline $\begin{array}{c}\text { Centre distance of } \\
\text { screws }\end{array}$ & 33.9 \\
\hline $\begin{array}{c}\text { Barrel bore } \\
\text { diameter }\end{array}$ & 42 \\
\hline Flight depth & 7.3 \\
\hline Clearance & 1 \\
\hline
\end{tabular}

The material from which the two screws were made was selected from the Ansys library. Figure 2 shows the properties of AISI 1045 Steel.

\begin{tabular}{|c|c|}
\hline \multicolumn{2}{|l|}{ Material } \\
\hline Material Name & AISI 1045 Steel, cold drawn, $19-32 \mathrm{~mm}(0.75-1.25 \mathrm{in})$ round \\
\hline Fluid & False \\
\hline Density & $7850000 \mathrm{~g} / \mathrm{m}^{\wedge} 3$ \\
\hline Ultimate Strength $(\mathrm{Pa})$ & $625000000 \mathrm{~Pa}$ \\
\hline Elastic Modulus ( $\mathrm{Pa}$ ) & $2.0500 \mathrm{E}+11 \mathrm{~Pa}$ \\
\hline Shear Modulus ( $\mathrm{Pa}$ ) & $8.0000 \mathrm{E}+10 \mathrm{~Pa}$ \\
\hline Poisson's Ratio & 0.29 \\
\hline Thermal Conductivity $(\mathrm{W} / \mathrm{m}-\mathrm{K})$ & $49.8 \mathrm{~W} / \mathrm{m}-\mathrm{K}$ \\
\hline
\end{tabular}

Fig. 2. Properties of AISI 1045 Steel

Figure 3 shows how the mesh superposition technique (MST) is used to simplify the mesh generation of the flow domain. Moreover, in order to avoid pressure peaks in regions were a large number of geometrical constraints exist, we modify the mass conservation equation so that the fluid becomes slightly compressible.
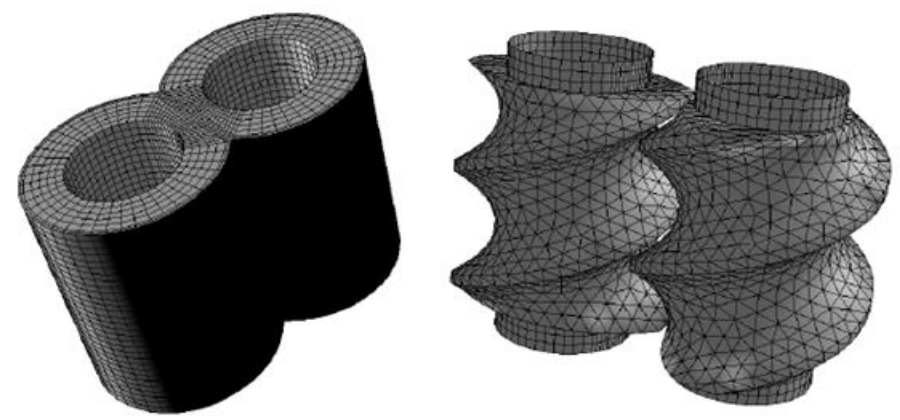

Fig. 3. Mesh of the flow domain and the two screws. 
It is essential to avoid incompatibilities between the motion of the moving parts and the boundary conditions imposed on the boundaries of the flow domain. In this example, we take into account the clearance between the screws and between the barrel wall and the screws. In order to obtain a good calculation of the pressure, it is important to mesh correctly the clearance area.

\section{Results and discussion}

Using the ANSYS Polyflow, there were obtained following results: the velocity field in a cutting plane parallel to rotation axes (fig. 4), pressure distribution on each screw (fig.5) and along the barrel wall (fig. 6)and also we observe unphysical pressure peaks in the clearance between the screws (fig.7) which it indicates that the mesh is not fine enough in this area. These results help us to better understand the phenomena that happen during the double-screw press process.

Figure 4 illustrates a cutting plane parallel to the rotation axis, which shows dispensing the material along the two screws. In areas with red and orange, the space between the two screws is the smallest and clutter of material is created.

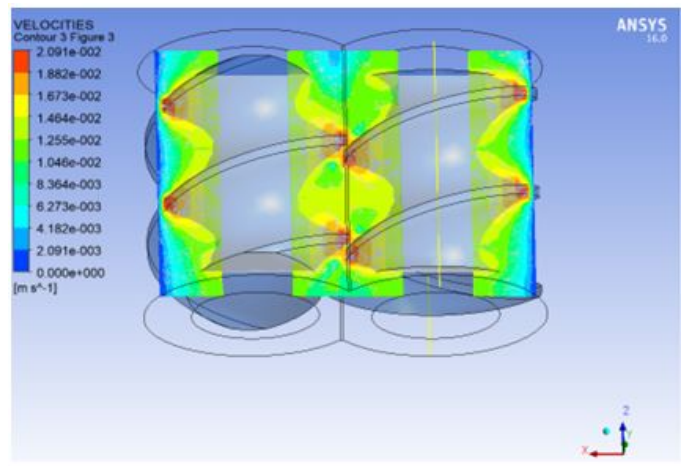

Fig. 4. Velocity field in plane.

Also, in the plane parallel to the axis of rotation, the pressure distribution on each screw is observed. In Figure 5 the area marked with red shows where the pressure reaches the highest value. These areas coincide with the crushing area of grape seeds.

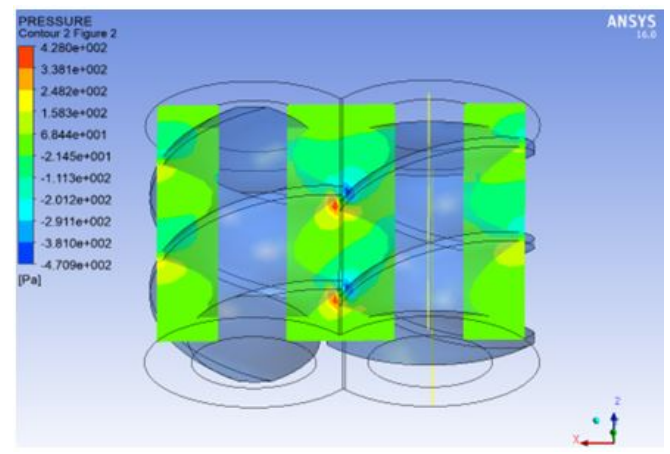

Fig. 5. Pressure field in plane. 
In contact with the pressed material is the wall of the pressing chamber. Figure 6 shows how the pressure acts during the pressing process in the feed direction of the material.

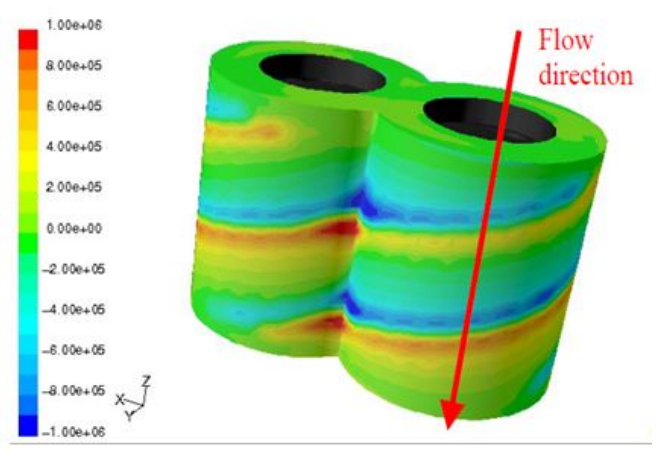

Fig. 6. Pressure field along barrel wall.

During the pressing process, the grape seeds advance into the pressing chamber according to the speed of rotation of the screws, figure 7 . At a higher rotational speed, it will increase the working capacity of the press but will decrease the oil yield.

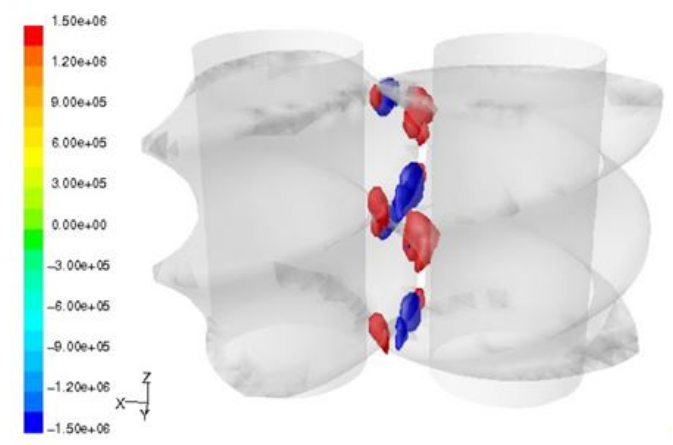

Fig. 7. Pressure peaks between screws.

In the direction of material advancement, the press screws suffer deformations over time, differently depending on the area in which we want to look. Larger deformations are in the cake escape area due to the exhaust nozzle that helps create more pressure, and smaller deformations are in the feed area. In figure 8, we can also see deformations of the twin-screw contour. 


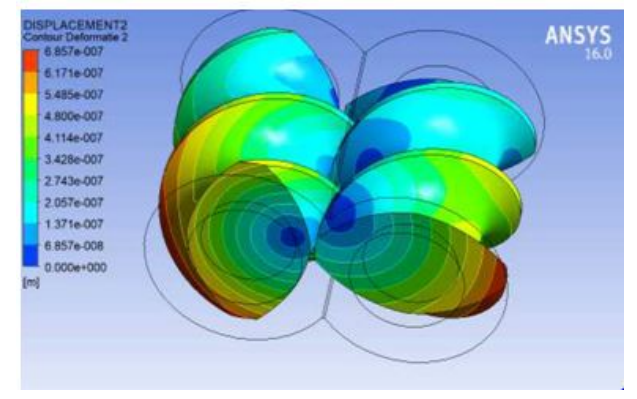

Fig. 8 Deformations of the twin-screw contour.

\section{Conclusions}

In the pressing process, the most important parameter is the pressure that is influenced by both the characteristics of the press and the characteristics of the material.

As expected, the pressure is high on the side of the screw pushing matter, while it is lower on the other side. In Figure 5, we notice red-marked pressure peaks in the space between the screws, indicating that there is a crushing of grape seeds. During the pressing process, the temperature increases due to the friction, which is a parameter that can lead to deformation of the screws and at the same time affects the characteristics of the oil.

Pressing grape seeds with a twin-screw press is a better option because the seeds have a higher amount of cellulose and a smaller quantity of oil and by using these presses, the yield of the oil is higher due to higher pressures used.

\section{Acknowledgement}

This work was supported by a grant of the Romanian Ministery of Research and Innovation CCDI - UEFISCDI, Project for financing excellence in RDI, contract no. 16PFE, within PNCDI III.

\section{References}

1. Achawangkul, Y., Maruyama, N., Hirota, M., Chaichana, C., Sedpho, S., Sutabutr, T. Evaluation on environmental impact from the utilization of fossil fuel, electricity and biomass producer gas in the double-chambered crematories. Journal of Cleaner Production.(2015)

2. Dutta, S., Karak, N., Saikia, J.P., Konwar, B.K. Biocompatible epoxy modified biobased polyurethane nanocomposites: Mechanical property, cytotoxicity and biodegradation. Bioresource Technology 100, 6391-6397.(2009).

3. Wu, X., Zhang, X., Yang, S., Chen, H., Wang, D., 2000. Study of epoxidized rapeseed oil used as a potential biodegradable lubricant. JAOCS, Journal of the American Oil Chemists' Society 77,561-563.

4. Owsianiak, M., Chrzanowski, Ł., Szulc, A., Staniewski, J., Olszanowski, A., OlejnikSchmidt, A.K., Heipieper, H.J., 2009. Biodegradation of diesel/biodiesel blends by a consortium of hydrocarbon degraders: Effect of the type of blend and the addition of biosurfactants. Bioresource Technology 100, 1497-1500. 
5. Rombaut, N., Savoire, R., Thomasset, B., Castello, J., Hecke, E. Van, \& Lanoisellé, J. 2015. Optimization of oil yield and oil total phenolic content during grape seed cold screw pressing. Industrial Crops \& Products, 63, 26-33.

6. Akin, Göü., Karuk elmas, Şü.Nihan., Arslan, F.N., Yilmaz, İ., Kenar, A. Chemometric classification and quantification of cold pressed grape seed oil in blends with refined soybean oils using attenuated total reflectance-mid infrared (ATR-MIR) spectroscopy, LWT - Food Science and Technology(2018)

7. Rombaut, N., et al., Optimization of oil yield and oil total phenolic content during grape seed cold screw pressing. Ind. Crops Prod. (2014).

8. Juan C. de Haro, Irene Izarra, Juan F. Rodríguez, Ángel Pérez, Manuel Carmona,2016. Modelling the epoxidation reaction of grape seed oil by peracetic acid. Journal of Cleaner Production 7197, 10.1016/j.jclepro.2016.05.015.

9. Singh, J., Bargale, P.C., 2000. Development of a small capacity double stagecompression screw press for oil expression. J. Food Eng. 43, 75-82.

10. Savoire, R., Lanoisellé, J.-L., Vorobiev, E., 2013. Mechanical continuous oilexpression from oilseeds: a review. Food Bioprocess Technol. 6, 1-16.

11. Lutterodt, H., Slavin, M., Whent, M., Turner, E., Yu, L., 2011. Fatty acid composition, oxidative stability, antioxidant and antiproliferative properties of selected cold-pressed grape seed oils and flours. Food Chem. 128, 391-399.

12. Maier, T., Schieber, A., Kammerer, D.R., Carle, R., 2009. Residues of grape (Vitis viniferaL.) seed oil production as a valuable source of phenolic antioxidants. Food Chem.112, 551-559,

13. Bouvier, J.M., Guyomard, P., Method and Installation for Continuous Extraction of a Liquid Contained in a Raw Material. EP 0914243 B1, 14 May (1996).

14. S. Isobe, F. Zuber, K. Uemura, A. Noguchi, „A New Twin-Screw Press Design for Oil Extraction of Dehulled Sunflower Seeds", Journal of the American Oil Chemists' Society, vol. 69, nr. 9, 884-889, 1992.

15. Kartika, I.A., Pontalier, P.Y., Rigal, L., 2010, Twin-screw extruder for oil processing of sunflower seeds: thermo-mechanical pressing and solvent extraction in a single step. Ind. Crops Prod. 32, 297 e304.

16. Dufaure, C., Leyris, J., Rigal, L., Mouloungui, Z., 1999a. A twin-screw extruder for oil extraction: I. Direct expression of oleic sunflower seeds. J. Am. Oil Chem. Soc. 76, $1073 \mathrm{e} 1079$

17. L. Rolle, F. Torchio, B. Lorrain, S. Giacosa, S. Río Segade, E. Cagnasso,V. Gerbi, P. Teissedre,2012, Rapid methods for the evaluation of total phenol content and extractability in intact grape seeds of cabernet-sauvignon: instrumental mechanical properties and ft-nir spectrum, J. Int. Sci. Vigne Vin, 46, n¹, 29-40, France 